\title{
EFFECT OF CRYOTHERAPY ON FUNCTIONAL PERFORMANCE OF SHOULDER
}

Varsha. Solanki ${ }^{{ }_{1}}$, Mugdha Oberoi ${ }^{2}$, Veena Krishnanand ${ }^{3}$.

${ }^{* 1}$ Research Intern, K.J. Somaiya College Of Physiotherapy, Everard Nagar, Sion, Mumbai, India.

${ }^{2}$ Assistant Professor, K.J. Somaiya College Of Physiotherapy, Everard Nagar, Sion, Mumbai, India.

${ }^{3}$ Professor and Head of Department, K.J. Somaiya College Of Physiotherapy, Everard Nagar, Sion, Mumbai, India.

\section{ABSTRACT}

Background: Shoulder joint is a complex joint producing wide range of motion. Joint receptors present in the capsule, ligaments transmit information about status of joint to the Central nervous system. Integrity of mechanoreceptors and CNS pathways play an important role to meet mobility and stability requirements. Receptors function to protect the joint from damage incurred by going in pathologic range of motion. Application of cryotherapy is common after acute shoulder injury as a part of rehabilitation. It is essential to study the effect of cryotherapy on functional performance of the shoulder joint and also to understand the safe recovery time post cryotherapy so as to return the subject back to activity.

Materials and Methods: 50 healthy subjects ( $n=25$ males $n=25$ females) were assessed using Functional Throwing Performance Index (FTPI) where the subject was told to throw the ball in a target at a measured distance using their dominant side. Then subject was given cryotherapy for 20 minutes followed by which the subject was reassessed immediately post cryotherapy, after $3 \mathrm{~min}, 5 \mathrm{~min}, 10 \mathrm{~min}$ and $15 \mathrm{~min}$.

Result: Data analysis showed a significant decrease $(p<0.0001)$ in mean FTPI from pre-cryotherapy FTPI $(0.5402$ $\pm 0.1741)$ to post-cryotherapy FTPI $(0.3787 \pm 0.1976)$. Also $3 \mathrm{~min}$ post-cryotherapy FTPI $(0.3958 \pm 0.1671), 5 \mathrm{~min}$ post-cryotherapy FTPI $(0.4706 \pm 0.1721)$ showed significant difference with pre-cryotherapy FTPI. Whereas, $10 \mathrm{~min}$ post-cryotherapy FTPI $(0.6063 \pm 0.1525)$ and $15 \mathrm{~min}$ post-cryotherapy FTPI $(0.6178 \pm 0.1466)$ showed no significant difference than pre-cryotherapy FTPI.

Conclusion: The study suggested that functional performance of shoulder, is affected post cryotherapy till $5 \mathrm{~min}$, and recovers to pre values by $10 \mathrm{~min}$.

KEY WORDS: Cryotherapy, FTPI, Proprioception, Shoulder Performance, recovery time.

Address for correspondence: Ms. Varsha. Solanki, Research Intern, K.J. Somaiya College Of Physiotherapy, Everard Nagar, Sion, Mumbai-400 022, India. E-Mail: varshasolanki.vs18@gmail.com

\section{Access this Article online}

Quick Response code

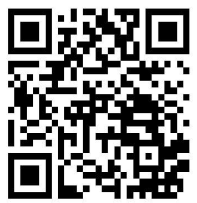

DOI: $10.16965 /$ ijpr.2017.170
International Journal of Physiotherapy and Research

ISSN 2321- 1822

www.ijmhr.org/ijpr.html

Received: 01-05-2017 Accepted: 05-06-2017

Peer Review: 02-05-2017 Published (0): 20-07-2017

Revised: None

Published (P): 11-08-2017

\section{INTRODUCTION}

Shoulder joint consists of Acromioclavicular, Sternoclavicular, Scapulothoracic and Glenohumeral joint. It is the most mobile joint in human body. Movement produced at the joint is FlexionExtension in Sagittal plane, Abduction-Adduction in Frontal plane and Internal and External rotation in Transverse plane. Shoulder complex also allows scapular protraction-retraction, elevation-depression [1]. Wide range of motion makes shoulder joint very unstable. This instability is compensated by rotator cuff muscles, tendons, ligaments and the glenoid labrum [1].

Shoulder joint relies on the proprioceptive feedback to maintain dynamic stability [1]. Proprioception is a subset of entire somatosensory system [2]. 
Joint position sense, kinesthesia and sense of force comprise proprioception and is important in neuromuscular control [2]. Neuromuscular control is based on subconscious information from mechanoreceptors present in the joint and processes this information within the central nervous system to produce a controlled and coordinated movement [2]. Receptors for joint position sense and movement are located in joint capsule, ligaments and tendons. Joint receptors function to protect the joint from damage incurred by going into pathologic range of motion [1].

Cryotherapy is defined as the therapeutic use of cold to reduce discomfort [3]. Cryotherapy reduces tissue temperature by withdrawing heat from the body to produce an analgesic effect $[2,4,5]$. Cryotherapy reduces pain, edema, inflammation, tissue temperature, metabolism, muscle stiffness, and nerve conduction velocity $[2,6]$.

Cryotherapy decreases cellular metabolism, which helps reduce the extent of secondary injury $[2,7]$. Cooling agents are used as a first-aid measure after trauma as an adjunctive tool in rehabilitation of musculoskeletal and neuromuscular dysfunction [2].

Aim of cryotherapy is primarily to reduce total amount of tissue damage, muscle spasm, swelling and pain to reduce disability and allow faster rehabilitation after injury [2]. Thus, it is important to understand how the modality affects functional performance. Hence, this study is aimed to study the effect of cryotherapy on functional perform-ance of shoulder in normal individuals.

\section{MATERIALS AND METHODS}

Approval for the study was taken from the institutional ethics committee and all the subjects provided their written informed consent. The study design was single group pre-test and post-test design conducted in the research lab of K.J. Somaiya College of Physiotherapy. 50 asymptomatic individuals $(N=50)$, females $(n=25)$ and males $(n=25)$ within the age group of 18-30 years were enrolled. Subjects with any musculoskeletal, neuromuscular and cardiovascular conditions or known allergy to ice were excluded. Each subject was assessed for Func- tional ability of the shoulder joint using the Functional Throwing Performance Index (FTPI)[8] followed by cryotherapy and reassessment for the outcome measure was done immediately post cryotherapy, after $3 \mathrm{~min}, 5 \mathrm{~min}, 10 \mathrm{~min}$ and $15 \mathrm{~min}$.

Functional Throwing Performance Index: The subject stood $4.57 \mathrm{~m}$ from the target, a $30.48 \times 30.48-\mathrm{cm}$ square on a wall at a height of $1.22 \mathrm{~m}$ from the floor. The object of the test is to throw a rubber playground ball $(50.8-\mathrm{cm}$ circumference) into the target as many times as possible over 30-second trials. (Fig.1 \& Fig.2). Before testing, subjects performed 8 throws as warm-up. Testing began immediately after warm-up and consisted of the subject throwing the ball into the target, catching the rebound off the wall, and repeating as many times as possible within 30 seconds. The FTPI was calculated as the number of throws within the target divided by the total number of balls thrown.

Cryotherapy Treatment: An ice bag treatment was employed as the cryotherapy modality in this study. Treatment duration was 20 minutes, based on accepted recommendations. A 1.15-L ice bag was filled with approximately $1500 \mathrm{~g}$ of cubed ice. The middle of the ice bag was centered over the acromion. Men were tested with their shirts off, and women with sports bra to allow maximal skin/ice bag interface. One double-length 6-in $(15.24-\mathrm{cm})$ elastic bandage was used to secure the ice bag. The subject was instructed to relax during the cryotherapy treatment to limit muscle activity [3]. Immediately after cryotherapy, the post-test assessments were performed (Fig.3).

Fig. 1: Showing the Target.

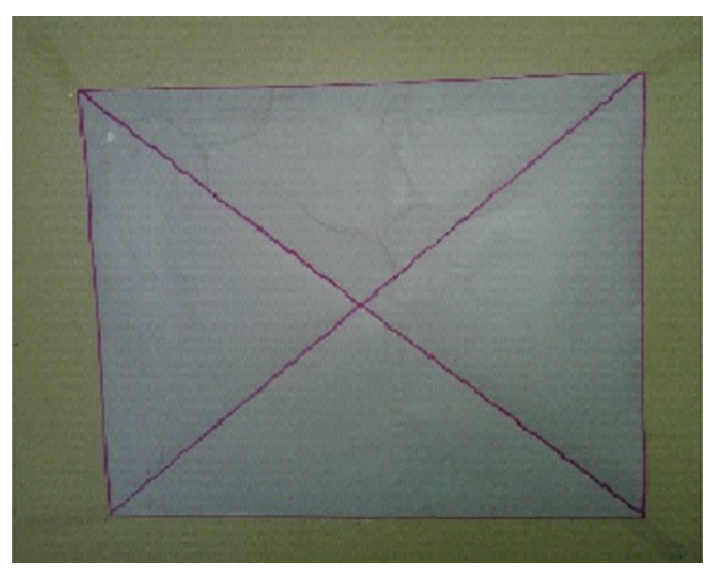


Fig. 2: Showing the subject throwing ball towards target.

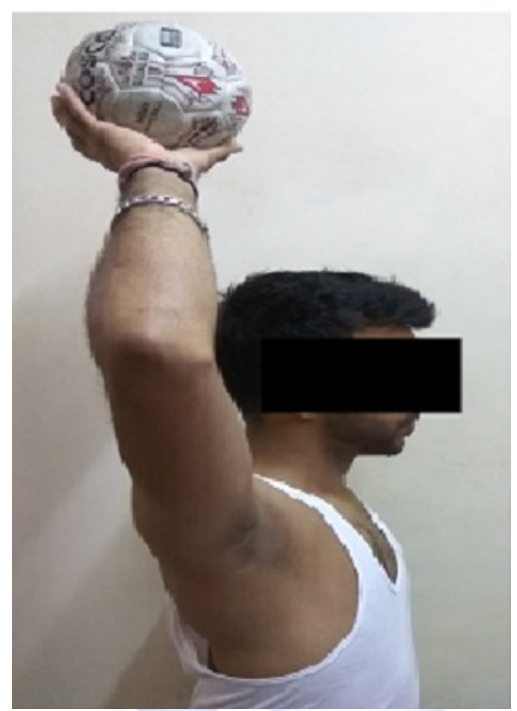

Fig. 3: Showing Application of Cryotherapy over shoulder.

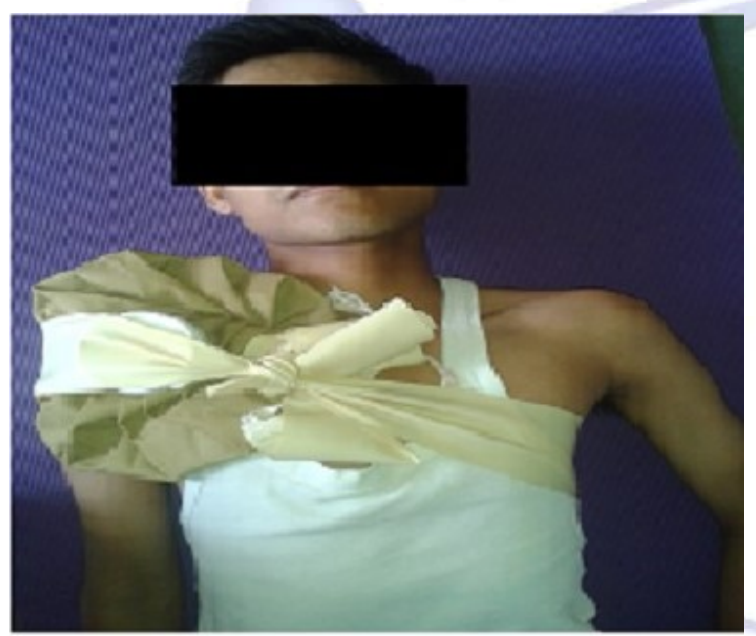

RESULTS

The data was analyzed using GraphPad Prism version 6 . As the data was not normally distributed, Wilcoxon signed rank test was used, to compare the values pre and post cryotherapy. Repeated measure ANOVA was used to compare post cryotherapy, $3 \mathrm{~min}, 5 \mathrm{~min}, 10 \mathrm{~min}, 15 \mathrm{~min}$ with pre cryotherapy values. Significance level was set at $95 \%$ confidence level for all statistical tests.

Data analysis showed a significant decrease $(p<0.0001)$ in mean FTPI from pre-cryotherapy FTPI $(0.5402 \pm 0.1741)$ to post-cryotherapy FTPI $(0.3787+0.1976)$. Also, $3 \mathrm{~min}$ post-cryotherapy FTPI $(0.3958 \pm 0.1671), 5 \mathrm{~min}$ post-cryptherapy FTPI $(0.4706 \pm 0.1721)$ showed significant difference with pre-cryotherapy FTPI, but $10 \mathrm{~min}$ post-cryotherapy FTPI $(0.6063 \pm 0.1525)$ and 15 min post-cryotherapy FTPI $(0.6178 \pm 0.1466)$ showed similar results as pre-cryotherapy FTPI.
Table 1: Functional Throwing Performance Index (FTPI) mean and Standard Deviation (SD).

\begin{tabular}{|l|l|l|}
\hline \multicolumn{1}{|c|}{ FTPI } & Mean & SD \\
\hline Pre Cryotherapy & 0.5402 & 0.1741 \\
\hline Post Cryotherapy & 0.3787 & 0.1946 \\
\hline 3min Post Cryotherapy & 0.3958 & 0.1671 \\
\hline 5 Min Post Cryotherapy & 0.4706 & 0.1721 \\
\hline 10min Post Cryotherapy & 0.6063 & 0.1525 \\
\hline 15min Post Cryotherapy & 0.6178 & 0.1466 \\
\hline
\end{tabular}

\section{DISCUSSION}

The purpose of our study was to study the effect of cryotherapy on functional performance of shoulder.

Cold is used to treat both acute and chronic injury $[2,3]$. Cryotherapy increases pain threshold, tissue viscosity, produces endorphins, readiness for physical activity, and general recovery from fatigue and stressful bouts of sports training [2]. Many researchers found that local cryotherapy impairs deep feeling in the body, and concluded that neuromuscular deficits occur after cryotherapy application and advised athletes to undertake dynamic training immediately after cryotherapy application [2]. In accordance with the study done by Herrera et al., nerve conduction velocity (NCV) after ice pack application decreased in sensory and motor NCV by $16.7 \mathrm{~m} / \mathrm{s}$ and $2.1 \mathrm{~m} / \mathrm{s}$, respectively $[2,6]$.

Criag Wassinger et al. in his study found significant difference in path of joint motion replication (PJMR) while moving from $90^{\circ} \mathrm{ABD}$-ER to the $20^{\circ}$ FLEX position [8]. Other authors have also found deficits in proprioception at the ankle and the knee after Cryotherapy $[9,10]$. Uchio et al identified decrease in nerve conduction velocity after cryotherapy as the culprit for altered proprioception.[10] Alterations in neuromuscular control can be associated with a deficiency in afferent pathways, central integration, or efferent pathways [11].

Neuromuscular control is the reflexive activation of muscular patterns to provide stability $[8,12]$. Since studies found deficits in PJMR and FTPI, it indicates that at the shoulder, cryotherapy may disrupt the motor control mechanism vital to not only functional ability and proprioception but also functional stability [8]. 
Anu Arora et al. assessed cricket players using FTPI where they found throwing accuracy was reduced after cryotherapy application, but at $10 \mathrm{~min}$ and $15 \mathrm{~min}$ post-cryotherapy there was no difference in throwing accuracy as compared to pre-cryotherapy throwing accuracy [13].

Kimberly Pritchard et al. suggested that athletes should not return to play immediately after cryotherapy treatments since functional performance may be adversely affected. Short duration cold application or progressive warm up should be implemented to prevent deleterious effect on functional performance [14].

Clinical Implication: According to the study done, functional performance is adversely affected by cryotherapy, till 10 minutes. Thus, caution should be observed when returning the subject back to function post use of cryotherapy.

\section{CONCLUSION}

Thus, the study concluded that there was a decrease in Functional Throwing Performance Index (FTPI) post-cryotherapy, which returned back to pre-cryotherapy values by $10 \mathrm{~min}$ post-cryotherapy.

\section{Conflicts of interest: None}

\section{REFERENCES}

[1]. Pamela K. Levangie, Cynthia C. Norkin. Joint Structure and Function: A Comprehensive Analysis 4th edition Page.231.

[2]. Mariusz Pawel Furmanek, Kajetan Slomka, Grzegorz Juras. The Effects of Cryotherapy on Proprioception System. Biomed Research International, Volume 2014, Article ID 69639.

[3]. Val Robertson, Alex Ward, John Low, Ann Reed. Electrotherapy Explained: Principles And Practice 4th Edition Page.357.
[4]. Janwantanakul P. Col pack/skin interface temperature during ice treatment with various levels of compression. Physiotherapy.2006;92:254-259.

[5]. Janwantanakul P. The effect of quantity of ice and size of cotact area on ice pack/skin interface temperature. Physiotherapy.2009;95:120-125.

[6]. Algafly AA, George KP. The effect of cryotherapy on nerve conduction velocity, pain threshold and pain tolerance. Br J Sports Med.2007;41:365-369.

[7]. Merrick MA, Rankin JM, Andres FA, Hinman CL. A preliminary examination of cryotherapy and secondary injury in skeletal muscle. Med Sci sports Exerc. 1999;31:1516-1521.

[8]. Craig A. Wassinger, Joseph B. Myers, Joseph M. Gatti, Kevin M. Conley, Scott M. Lephart. Proprioception and Throwing Accuracy in the Dominant Shoulder After Cryotherapy. Journal Of Athletic Training 2007;42(1):84-89.

[9]. Hopper D, Whittigton D, Davies J. Does ice immersion influence ankle joint position sense? Physiother Res Int. 1997;2:223-226.

[10]. Uchio Y, Ochi M, Fujihara A, Adachi N, Iwasa J, Sakai $Y$. Cryotherapy influences joint laxity and position sense of the healthy knee joint. Arch Phys Med Rehabil. 2003;84:131-135.

[11]. Myers JB, Lephart SM. Sensorimotor deficits contributing to glenohumeral instability. Clin Orthop Pelat Res. 2002;400:98-104.

[12]. Riemann BL, Lephart SM. The sensorimotor system, Part I: the physiologic basis of functional joint stability. J Athl Train. 2002;37:71-79.

[13]. Anu Arora, Anup Pednekar, Sujata Yardi. Effect of Cryotherapy on Throwing Accuracy of Shoulder Joint in Cricket Players. Indian Journal of Physiotherapy \& Occupational Therapy-An International Journal 2014;8(01-04):159-163.

[14]. Kimberly A. Pritchard, Susan A. Saliba. Should Athletes Return to Activity After Cryotherapy? Journal Of Athletic Training 2014;49(1):95-96.

How to cite this article:

Varsha. Solanki, Mugdha Oberoi, Veena Krishnanand. EFFECT OF CRYOTHERAPY ON FUNCTIONAL PERFORMANCE OF SHOULDER.Int Physiother Res 2017;5(4):2194-2197. DOI: 10.16965/ijpr.2017.170 